\title{
REFLEXÕES SOBRE AS CONTRIBUIÇÕES DE UM PROJETO DE EXTENSÃO PARA A FORMAÇÃO INICIAL NO CURSO DE LICENCIATURA EM PEDAGOGIA
}

\section{REFLECTIONS ABOUT THE CONTRIBUTIONS OF AN OUTREACH PROJECT FOR THE INITIAL EDUCATION IN THE PEDAGOGY COURSE}

Karina Regalio Campagnoli** Denise Puglia Zanon**

\begin{abstract}
RESUMO:
$\mathrm{O}$ conhecimento sobre projeto extensionista e suas possíveis contribuições para a formação inicial de licenciandos em Pedagogia na Universidade Estadual de Ponta Grossa - UEPG - PR é a temática deste artigo, tendo em vista as recentes discussões sobre curricularização da extensão. Intenciona-se refletir sobre contributos do projeto extẹnsionista denominado: "A dimẹnsão didática no trabalho docente: as relações entre ensinar, aprender, pesquisar e avaliar", desenvolvido junto aos acadêmicos de diversas licenciaturas na UEPG. Compreendendo a extensão como espaço oportuno para o estabelecimento de dialogicidade entre universidade e comunidade, as consideracões aqui expressas trazem à baila aspectos relativos ao sentido da extensão na formação do licenciando, tornando-a mais significativa, observando-se as contribuições de André (2010), Garcia (2012), Gatti $(2013,2014)$, entre outros. Constata-se que a extensão universitária na formacão inicial de professores propicia aos licenciandos, além do contato com, a percepção sobre a realidade docente, favorecendo a construção do conhecimento, envolvendo todos os partícipes.
\end{abstract}

Palavras-chave: Extensão Universitária; Didática; Formação de Professores.

\begin{abstract}
:
The theme of this article is the knowledge about outreach projects and their possible contributions to the initial education of undergraduate students in Pedagogy at the Ponta Grossa State University - UEPG - PR, taking into consideration the recent discussions about curricularisation of outreach activities. The aim is to reflect about the contributions of the outreach project called: "The Didactic Dimension in Teaching: The Relationship between Teaching, Learning, Researching and Evaluating", developed with undergraduate students from various courses at the UEPG. Outreach activities are seen as adequate spaces for the dialogue between the university and the community. The considerations presented in this article, highlight aspects related to the meaning of outreach projects for the education of undergraduate students, making it more meaningful. The study was based on the contributions of André (2010), Garcia (2012), Gatti $(2013,2014)$, among others. It is observed that outreach university activities in teachers' initial education provides the undergraduates, not only the contact with the teaching reality, but also the perception about it, favoring the construction of knowledge and the involvement of all participants.
\end{abstract}

Keywords: University Outreach Project; Didactics; Teacher Education. 


\section{Introdução}

Pretende-se, neste artigo, apresentar aspectos relativos à extensão universitária e formação de professores acerca dos possíveis benefícios propiciados por um projeto dessa natureza, especialmente junto aos licenciandos do Curso de Pedagogia da Universidade Estadual de Ponta Grossa (UEPG).

Opta-se pela abordagem de pesquisa de cunho qualitativo, sendo que para a compreensão dos dados expressos nas narrativas, recorremos à literatura de Bardin (1977), adotando a análise de conteúdo: "Uma técnica que consiste em apurar descrições de conteúdos muito aproximativas, subjectivas, para pôr em evidência com objectividade a natureza e as forças relativas dos estímulos a que o sujeito é submetido." (BARDIN, 1977, p. 34).

$\mathrm{O}$ referido projeto extensionista intitula-se "A dimensão didática no trabalho docente: as relações entre ensinar, aprender, pesquisar e avaliar", e conforme o título expressa, objetiva-se, nesta proposta, evidenciar a necessária articulação entre os elementos do processo didático, potencializando discussões e reflexões sobre Didática e docência no contexto da formação inicial de professores.

Para o desenvolvimento da ação acima mencionada, os partícipes são professoras da UEPG, lotadas no Departamento de Pedagogia (DEPED); acadêmicos das diversas licenciaturas dessa universidade, dentre as quais Pedagogia, História, Física, Letras, além de professores da Educação Básica - ensino público e privado, do município de Ponta Grossa - PR.

É pertinente a afirmação de Rodrigues et al. (2013, p. 143) no sentido de que as ações extensionistas fortalecem as relações entre Universidade e sociedade, priorizando a reciprocidade, compreendendo que: "o ensino rompe as barreiras da sala de aula e sai do ambiente fechado da Universi dade, para que haja a troca de informações provenientes do ambiente primordial. Assim, o conteúdo passa a ser multi, inter e transdisciplinar'.

Nesse sentido, as diretrizes para as ações extensionistas expressas na Política Nacional para Extensão (FORPROEX, 2012), destacam: a interação dialógica, a interdisciplinaridade e o impacto na formação do estudante, orientações que são observadas na definição dos encaminhamentos neste projeto.

A partir dessa perspectiva, neste projeto privilegiam-se momentos e espaços para discussão e estudos sobre o processo ensino-aprendizagem, observações de diferentes aulas no contexto escolar, reconhecendo-se a complexidade de que se reveste 0 ato de ensinar, propiciando-se o desenvolvimento de ações conjuntas entre instituição de Ensino Superior e estabelecimentos de ensino, de modo a se gerarem novos saberes e compreensões sobre a docência.

São pertinentes as afirmações de Garcia (2012, p. 41, grifo do autor):

Sabe-se que a universidade nasceu para cumprir o papel primeiro que é o de ensinar, de preparar profissionais para a sociedade para que exerçam sua profissão, seja ela qual for, todavia se acreditamos que devemos ir para além da técnica, na direção do compromisso social, precisamos fazer bom uso das atividades acadêmicas para que essas acrescentem algo para dar sentido a uma prática, entendida para além do caráter utilitário, na direção da práxis.

Em consonância com as colocações expressas pela autora, registra-se a compreensão sobre formação de professores, evidenciando que o projeto extensionista aqui descrito prioriza, em suas ações, contribuições para a formação de licenciandos e professores que atuam na Educação Básica. Assim, é necessário salientar:

A Formação de Professores é a área de conhecimentos, investigação e de propostas teóricas e práticas que, no âmbito da Didáctica e da Organização Escolar, estuda os processos através dos quais os professores - em formação ou em exercício - se implicam individualmente ou em equipe, em experiências de aprendizagem através das quais adquirem ou melhoram os seus conhecimentos, competências e disposições, e que lhes permite intervir profissionalmente no desenvolvimento do seu ensino, do currículo e da escola, com o objectivo de melhorar a qualidade da educação que os alunos recebem. (MARCELO GARCÍA, 1999, p.26).

O posicionamento do autor suscita a reflexão sobre a formação de professores, que se configura como processo individual e coletivo, sendo que especialmente este último propicia o estabelecimento de relações dialógicas entre os profissionais e futuros professores, no sentido de que estas potencializem a aquisição, ampliação, ressignificação de conhecimentos que sejam evocados nas situações de ensino, fortalecendo o processo de tomada de decisões nas vivências/experiências na profissão.

Nessa direção, localizam-se as ações do projeto de extensão, reconhecendo que se conectam à instituição escolar, tendo como balizador o entendimento sobre extensão, registrado no documento Política Nacional de Extensão Universitária, destacando-se:

A Extensão Universitária, sob o princípio
constitucional da indissociabilidade entre ensino,
pesquisa e extensão, é um processo interdisciplinar,
educativo, cultural, científico e político que promove a
interação transformadora entre Universidade e outros
setores da sociedade. (FORPROEX, 2012, p.15).

Sobre a necessária conexão entre as diferentes esferas, representadas pela universidade e por escolas, com seus atores, incluindo os gestores educacionais, Gatti (2013-2014, p. 42) explica que:

O debate sobre toda essa situação na formação inicial
de professores para a educação básica tem mobilizado
os profissionais da educação, bem como os gestores
estaduais e municipais que respondem diretamente
pelas escolas. O que se necessita é, a partir da situação
mapeada, do conjunto de ideias e ideais postulados,
criar condições concretas para um novo tipo de
formaçãao inicial, no ensino superior, para a docência na
educação básica. Há necessidade de melhor estruturar,
qualificar e avaliar o trabalho desenvolvido nas
licenciaturas, na formação inicial de docentes para a
educação básica. É tarefa de ontem, mas ousar mudar
de fato não é uma questão simples nos contextos de
nossas instituições e das normatizações.

Assim, o projeto de extensão apresenta-se como uma oportunidade para que os licenciandos estejam, durante seu percurso formativo, em contato com as práticas pedagógicas desenvolvidas nas escolas, acompanhando os professores da Educação Básica, dedicando-se ao estudo de diferentes referenciais que subsidiem as observações, a ação didática, com a mediação das professoras formadoras no projeto, possibilitando a reflexão sobre as diferentes dimensões que compõem a docência. 


\section{Revisão de Literatura}

Neste trabalho, apresentam-se compreensões relativas à origem e ao desenvolvimento da extensão, bem como às aproximações entre esta e a formação de professores, destacando-se inicialmente um aspecto curioso sobre a extensão. Esse fato versa sobre a ocorrência, em Portugal, desde 1269, de alguns registros sobre atividades que podem ser caracterizadas como extensionistas, cujo objetivo era propagar os ideais religiosos para além do ambiente escolar, fato que inspirou o desenvolvimento de ações pautadas nesse modelo em vários países (ROCHA, 2001).

Dessa forma, o primeiro registro oficial de ações de extensão remete-se à Inglaterra, há quase dois séculos, que tinham o propósito de mudar o rumo dos conhecimentos naquele contexto histórico específico (RODRIGUES et al., 2013). Sobre isso, os autores esclarecem:

A extensão surgiu na Inglaterra do século XIX, com a intenção de direcionar novos caminhos para a sociedade e promover a educação continuada. Nos dias atuais, surge como instrumento a ser utilizado pela Universidade para a efetivação do seu compromisso social. A construção do conceito de extensão tem como base persuadir a Universidade e a comunidade proporcionando benefícios e adquirindo conhecimentos para ambas as partes. (RODRIGUES et al., 2013, p. 142).

Concordando com os preceitos apresentados no excerto acima, ainda acrescenta-se que é significativo o papel da extensão universitária no que respeita às possíveis contribuições para a vida em sociedade. Além disso, salientam-se os saberes advindos da comunidade para a instituição de ensino superior. Sobre isso, Rodrigues et al. (2013) ressaltam quão importante, por parte da Universidade, é explicitar sua compreensão sobre extensão, tendo em vista que essas ações desenvolvem-se junto à comunidade numa relação de reciprocidade, com benefícios para todos os partícipes.

Discorrendo sobre a relevância social das atividades extensionistas, é recorrente assinalar que estas não se desenvolvem isoladamente, desconectadas do ensino e da pesquisa, tornando-se pertinente evidenciar, então, o disposto no documento Política Nacional de Extensão Universitária (2012), ao evidenciar a imprescindível articulação entre ensino, pesquisa e extensão:

\begin{abstract}
A diretriz Indissociabilidade Ensino - Pesquisa Extensão reafirma a Extensão Universitária como processo acadêmico. Nessa perspectiva, o suposto é que as ações de extensão adquirem maior efetividade se estiverem vinculadas ao processo de formação de pessoas (Ensino) e de geração de conhecimento (Pesquisa). (FORPROEX, 2012, p. 19).
\end{abstract}

Complementando as ideias já expressas sobre extensão, nas discussões empreendidas por Fujita e Barraviera (2014, p. 3), estes asseveram que a extensão constitui-se em uma via de mão dupla, no sentido de que a comunidade acadêmica, em contato com as instituições, com a sociedade, tem a possibilidade de "elaboração de práxis de um conhecimento acadêmico. No retorno à Universidade, docentes e discentes trarão um aprendizado que, submetido à reflexão teórica, será acrescido àquele conhecimento".

Em Freire (1983, p. 20) localiza-se o entendimento sobre extensão que se adota neste texto:
O termo extensão, na acepção que nos interessa aqui, indica a ação de estender em sua regência sintática de verbo transitivo relativo, de dupla complementação estender algo a [...] a ação de extensão se dá no domínio do humano e não do natural, o que equivale dizer que a extensão de seus conhecimentos e de suas técnicas se faz aos homens para que possam transformar melhor o mundo em que estão, o conceito de extensão também não tem o sentido do ponto de vista humanista. E não de um humanismo abstrato, mas concreto, científico.

Sobre a interação, representada pelas vivências propiciadas em ações extensionistas entre professores da Educação Básica, licenciandos e docentes das instituições de Ensino Superior, assim como a parceria nas vivências no ambiente educacional, Freire (2014, p. 95-96) afirma com veemência que:

[...] o educador já não é o que apenas educa, mas o que, enquanto educa, é educado, em diálogo com o educando que, ao ser educado, também educa. Ambos, assim, se tornam sujeitos do processo em que crescem juntos e em que os "argumentos de autoridade" já não valem. Em que, para ser-se, funcionalmente, autoridade, se necessita de estar sendo com as liberdades e não contra elas. (Itálico do autor).

Nesse sentido, compreende-se a extensão como uma das possibilidades para contribuir na formação inicial de professores, reconhecendo que constitui um processo complexo e requer reflexão e análise por parte dos atores que a compõem.

Sobre a formação de professores, Gatti (20132014, p. 43) colabora nesta discussão, ao explicitar que o desenvolvimento dos professores como profissionais se dá por meio da formação inicial na graduação, pelas experiências vivenciadas sobre a prática docente, sendo que estas concretizam-se no exercício da profissão, destacando que:
[...] é preciso ressaltar que esse desenvolvimento profissional parece, nos tempos atuais, configurar-se com condições que vão além das competências operativas e técnicas associadas ao seu trabalho no ensino, tornando-se uma integração de modos de agir e pensar, implicando um saber que inclui a mobilização não só de conhecimentos e métodos de trabalho, como também de intenções, valores individuais e grupais, da cultura da escola; inclui confrontar ideias, crenças, práticas, rotinas, objetivos e papéis, no contexto do agir cotidiano, com as crianças e jovens, com os colegas, com os gestores, na busca de melhor formar os alunos, e a si mesmos.

Nesse sentido, o projeto de extensão relatado nesse trabalho visa colaborar com a formação inicial de professores para a Educação Básica, representado pelos cursos de licenciatura da universidade em questão, especialmente com o curso de licenciatura em Pedagogia. Corroborando com essa perspectiva, André (2010, p. 176) justifica:

\begin{abstract}
Queremos conhecer mais e melhor os professores e seu trabalho docente porque temos a intenção de descobrir os caminhos mais efetivos para alcancar um ensino de qualidade, que se reverta numa aprendizagem significativa para os alunos. Isso supõe, por um lado, um trabalho colaborativo entre pesquisadores da universidade e os professores das escolas, e por outro lado um esforço analítico muito grande, seja no interior dos grupos de pesquisa, seja entre grupos para reunir elementos que ajudem a reestruturar as práticas de formação.
\end{abstract}

Além disso, Rodrigues et al. (2013, p. 146) ressaltam que, por meio destas ações, os acadêmicos entram em contato com a comunidade, desenvolvem as atividades, colocam em movimento os conhecimentos apreendidos na 
graduação, reconhecendo que um dos objetivos da extensão é a promoção da melhoria da qualidade de vida de todos os participantes, com vistas à mudança social.

Sobre as ações de extensão, é importante clarificar que estas propiciem aprendizados para todos os partícipes, desmistificando a ideia de que em ações dessa natureza a universidade é detentora do conhecimento, mas que por meio de ações colaborativas, comunidade, instituições diversas, profissionais da universidade e graduandos socializam saberes, dialogam e aprendem. Ao propiciar aprendizados para professores e licenciandos, são esclarecedoras as palavras de André (2010, p. 76):

[...] a formação docente tem que ser pensada como um aprendizado profissional ao longo da vida, o que implica envolvimento dos professores em processos intencionais e planejados, que possibilitem mudanças em direção a uma prática efetiva em sala de aula.

Pensando sobre a formação de professores e a extensão, são pertinentes as palavras de Garcia (2012) ao discorrer sobre o desenvolvimento das atividades de extensão realizadas no Brasil. A autora destaca alguns movimentos desencadeados no Rio Grande do Norte, nos anos de 1960, liderados por Paulo Freire, o qual lançou aos trabalhadores uma proposta de ensino para o processo de alfabetização, salientando as ações junto à comunidade. No entanto, a autora enfatiza que:

Apesar de todo o movimento que se apresentava no país, a reforma universitária colocou-se na contramão do clamor social e acabou por submeter as ações de engajamento político-social à segurança nacional, atitude típica do período pós 1964. No final da década de 1960, em função da extensão fazer parte, essencialmente, de atividades extracurriculares, com forte participação popular e comunitária, acaba sendo submetida também à segurança nacional. (GARCIA, 2012, p. 28).

Em vista disso, presenciou-se uma dispersão dos estudantes, em virtude das ações do Estado autoritário, o qual passa a dominar toda e qualquer ação extensionista, na perspectiva de desconstruir a concepção de extensão participativa e crítica, que se preocupava, discutia e dialogava sobre os problemas sociais do país (GARCIA, 2012).

Nesse sentido, a mesma autora ainda esclarece que "O CRUTAC [Centro Rural Universitário de Treinamento e Ação Comunitária] daria à universidade brasileira um novo perfil voltado à comunidade, para além dos seus próprios muros, menos tecnicista e mais voltado à realidade regional". Vale ressaltar que o programa chamado CRUTAC foi uma iniciativa do governo federal, organizada após o Golpe de 1964, com o intuito de "manter" os projetos de extensão no Brasil, porém de modo controlado (GARCIA, 2012).

Certamente, a posição que se defende nesse artigo assenta-se na compreensão sobre o desenvolvimento de uma postura ativa e crítica por parte dos acadêmicos, atuando junto à comunidade, no caso, as escolas de Educação Básica, vivenciando seus problemas e colaborando para o enfrentamento e a possível superação dos entraves que permeiam as práticas pedagógicas, configurando um movimento rico de troca de experiências e aprendizados. Seguindo essa perspectiva, concordando com Rodrigues et al. (2013, p. 145), ao assinalarem que:

A formação e a produção de conhecimento que envolve professores e alunos de forma dialógica é um grande e importante resultado da extensão universitária, em que permite que o aluno tenha suaprópria opinião e que possa questionar sempre que necessário.

Com o advento dos anos 2000, a extensão voltou a ser pauta nos órgãos oficiais de educação no Brasil e, segundo Garcia (2012, p. 32):

Nesse período, já havia um diferencial nos
organogramas das universidades, surgiam as pró-
reitorias ou vice-reitorias de extensão. Essa
institucionalização acabou gerando o início de outra
organização da extensão, o que permitiu o surgimento
de programas e projetos não mais de caráter
circunstancial, mas de cunho permanente,
desmitificando aos poucos aquela visão somente de
prestação de serviços pontuais e reativas aos
movimentos sociais à qual a extensão estaria vinculada.

Compreendendo a extensão pelo viés de articulação com a comunidade, do estabelecimento de relação dialógica, de escuta dos partícipes, especificamente aqui, em relação às instituições de Educação Básica e sobre os alunos das salas de aula em que os acadêmicos realizam parte das atividades constituintes desse projeto de extensão, é pertinente o posicionamento de Freire (2006, p. 43) sobre o diálogo, discernindo que: "Ser dialógico é não invadir, é não manipular, é não sloganizar. Ser dialógico é empenharse na transformação constante da realidade."

Portanto, as aproximações estabelecidas entre Universidade e Escola primam pela relação dialógica e pela relevância do contato dos licenciandos com a realidade escolar. Assim, nas palavras de Gatti (20132014 , p. 40), é possível refletir sobre o significado do contato dos futuros professores com a escola:

[...] esses alunos não são seres abstratos, mas pessoas que partilham sua constituição com ambiências sociais cada vez mais complexas, o trabalho dos professores demanda uma compreensão mais real sobre eles e sobre a própria instituição escola, em uma formação que lhes permita lidar com as condições concretas de aprendizagem nas ambiências das salas de aula.

Nesse sentido, este projeto de extensão demonstra que as atividades propostas oportunizam ricos momentos de formação acadêmica para os licenciandos que dele fazem parte, articulando ações de cunho didático nas escolas de Educação Básica. Além disso, destaca-se a relevância do espaço para a troca de experiências e reflexões sobre as atividades docentes, além da participação no grupo de estudos, configurando, portanto, atividades de pesquisa sobre a própria prática docente, para os acadêmicos e professores atuantes na escola.

No movimento, diálogo e ações conjuntas entre professores da Universidade, licenciandos e professoras da Educação Básica, desenvolvem-se e descortinam-se caminhos e possibilidades para a formação docente, evidenciando que:

Os professores desenvolvem sua condição de profissionais tanto pela sua formação básica na graduação, como por suas experiências com a prática docente, iniciada na graduação e concretizada no trabalho das redes de ensino. (GATTI, 2013-2014, p.43).

Certamente, as experiências propiciadas pela instituição de Ensino Superior no processo formativo de seus licenciandos precisam revestir-se de significado, contemplando vivências e experiências concretas no ambiente escolar, primando pela reflexão constante sobre os saberes diversos que compõem a docência. Nesse sentido, o projeto extensionista aqui descrito busca esta aproximação. 
Conhecendo o projeto de extensão "A dimensão didática no trabalho docente: as relações entre ensinar, aprender, pesquisar e avaliar"

O projeto de extensão "A dimensão didática no trabalho docente: as relações entre ensinar, aprender, pesquisar e avaliar" teve sua primeira edição em 2012, a partir da iniciativa de um grupo de professoras do Departamento de Pedagogia (DEPED), da Universidade Estadual de Ponta Grossa, originando-se de reflexões e diálogos entre essas professoras sobre os relatos de licenciandos nas aulas das disciplinas de Didática e Prática Pedagógica. Emergiram desses diálogos certas inquietações sobre o processo de formação acadêmica e a necessária articulação desse com o contexto real das escolas de Educação Básica. Sobre essa articulação, Garcia (2012, p. 19) defende:

[... a indissociabilidade entre o Ensino, a Pesquisa e a Extensão [..., acreditando] em uma Extensão que seja composta por ações em que sejam imprescindíveis: o professor, o aluno e a comunidade, comunidade essa que não seja compreendida como receptora dos saberes da universidade, mas, que possa construir "com" a universidade um conhecimento com outro olhar sobre os fazeres e saberes dentro e fora do espaço acadêmico.

Assim nasceu o referido projeto, caracterizado, primordialmente, pela busca de encaminhamentos e proposições, com vistas a contribuir com a formação acadêmica, revestida de significados diversos daqueles já consolidados nos projetos de cursos.

O referido projeto de extensão tem como partícipes professoras idealizadoras dele, professores da Educação Básica pertencentes ao quadro docente das escolas parceiras dessas atividades, bem como os acadêmicos de diferentes licenciaturas.

Dessa forma, com esse objetivo, dentre as diversas ações do projeto, destacam-se: a) Observação participativa dos licenciandos nas escolas de Educação Básica; b) Elaboração de narrativas pelos acadêmicos a partir de cada período de observação nas escolas; c) Encontros mensais entre todos os participantes do referido projeto; d) Elaboração de sínteses individuais por todos os integrantes, a partir dos encontros mensais do grupo; e) Intervenções didático-pedagógicas pelos acadêmicos nas escolas, em presença dos professores regentes das respectivas turmas. O projeto caracteriza-se pela realização de atividades individuais e coletivas, constituindo-se em momentos de observação diretamente na escola, permeados por discussões e reflexões com o grupo de professores, tanto da universidade, quanto da Educação Básica. Vale ressaltar que as narrativas são elaboradas pelos acadêmicos e encaminhadas para as docentes da UEPG. Já as sínteses são elaboradas por todos os participantes do projeto e compartilhadas em uma rede social de acesso restrito.

Nesse sentido, as reuniões de estudos mensais, caracterizadas como grupo de estudos, reúnem todos os participantes do projeto, conforme já mencionado, oportunizando a socialização das experiências, debatendo sobre temas pertinentes à didática, à prática pedagógica, tornando, assim, a construção do conhecimento docente mais sólida, uma vez que:

Educar na vida compreende atividade muito complexa, trata-se de tema amplo e que merece atenção, de modo que, quando se pensa em instituições de ensino superior, mais ainda se deveria pensar sobre como ocorre a relação entre conhecimento e sociedade, pois, a universidade tem como objetivo maior a formação de sujeitos, e é nesses sujeitos que reside a semente da mudança. (GARCIA, 2012, p. 17).

Figura 1 - Grupo de Estudos.

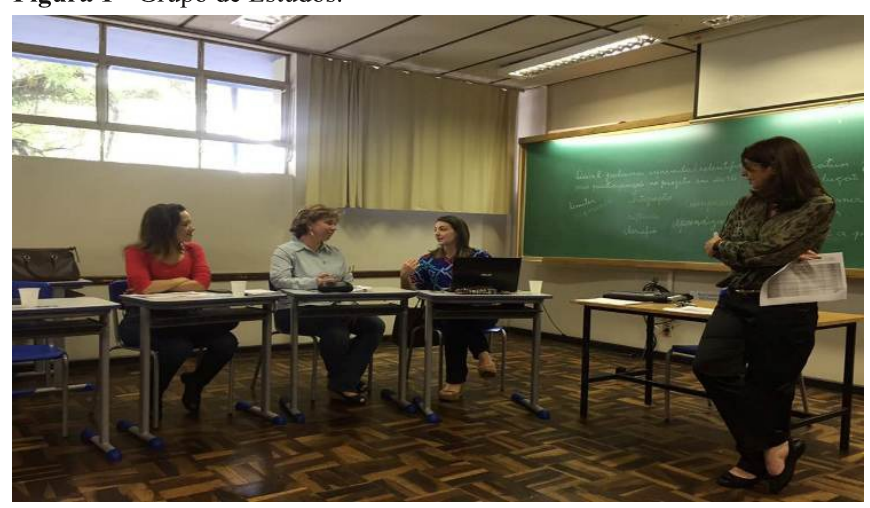

Fonte: Acervo das autoras.

É importante ressaltar que este projeto encontra-se, no ano de 2018, em sua quarta edição e, por determinação dos regulamentos da Pró-Reitoria de Extensão da UEPG (PROEX), a proposta deve ser submetida para avaliação e reedição a cada dois anos.

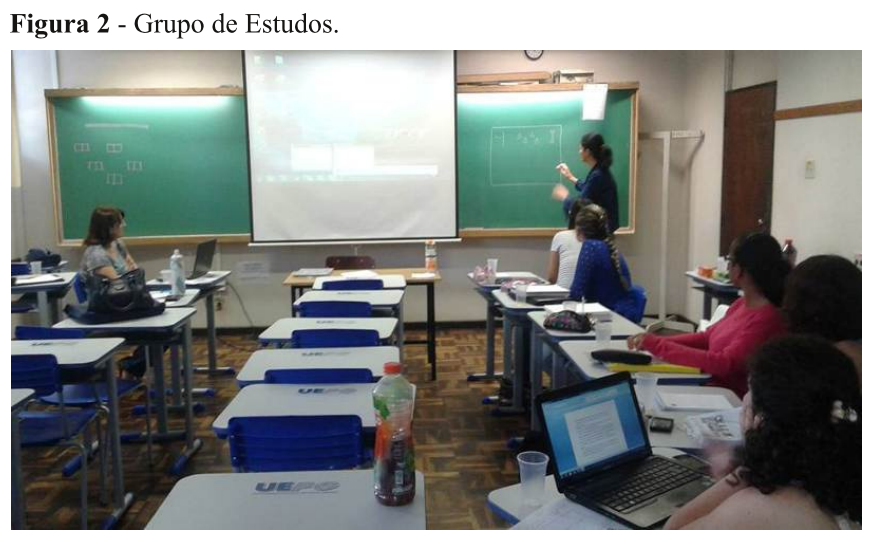

Fonte: Acervo das autoras.

Com vistas a enriquecer o processo de formação profissional e acadêmica, os licenciandos acompanham os professores da Educação Básica, nas modalidades de Educação Infantil ao Ensino Médio. Presenciam a ação didática dos professores, cooperando em diferentes momentos da aula, mostrando-se disponíveis para realizar a denominada "observação participativa", sendo que deste acompanhamento e participação, das reuniões de estudos e planejamento emergem as narrativas. Na Figura 1 é possível visualizar as ações do projeto e o movimento desencadeado:

Figura 3 - Ações do projeto e o movimento desencadeado.

ESTUDOS/

REFLEXŐES

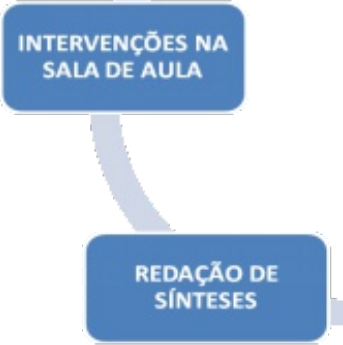

PRODUÇÃO DE NARRATIVAS

Fonte: As autoras (2018) 
Mediante as atividades desenvolvidas, "O trabalho centra-se na extensão pelas possibilidades da relação mais próxima dos estudantes com a sociedade na qual vão atuar, profissionalmente e como sujeitos, por meio de ações extensionistas" (GARCIA, 2012, p. 37). Essa iniciativa também é defendida pela autora ao enfatizar que cabe à extensão:

\begin{abstract}
Estabelecer caminhos que possibilitem o compartilhamento de saberes e fazeres da sociedade e da universidade parece ser uma proposta que se justifica pela necessidade cada vez maior de se criar ações que aproximem a universidade e a sociedade por meio de relações concretas. A extensão como via de mão dupla, pode ser um elo dessas relações, tornandose articuladora de uma práxis que caminhe na direção da ressignificação do saber acadêmico. (GARCIA, 2012, p. 18).
\end{abstract}

Após o acompanhamento pedagógico de cada período em sala de aula, os acadêmicos elaboram uma narrativa na qual discorrem sobre as atividades realizadas no dia de observação, anotando atitudes positivas que os docentes tiveram em sala de aula e demarcando iniciativas que cooperam com o alcance do processo ensino-aprendizagem, de modo a levantar novos pontos para debate.

A frequência para o acompanhamento das atividades docentes pelos acadêmicos nas escolas de Educação Básica é de um período durante a semana manhã, tarde e/ou noite - totalizando quatro horas de atividades semanais no ambiente escolar.

Como parte do processo de avaliação dos acadêmicos que participam desse projeto, além da presença, compromisso, responsabilidade e atitude colaborativa e cooperativa com o professor que oportuniza o espaço de observação em sala de aula, tem-se também a realização de uma intervenção didática, que ocorre a partir da definição conjunta entre professor e licenciando, no momento em que a considerarem pertinente.

Figura 4 - Intervenções em sala de aula.

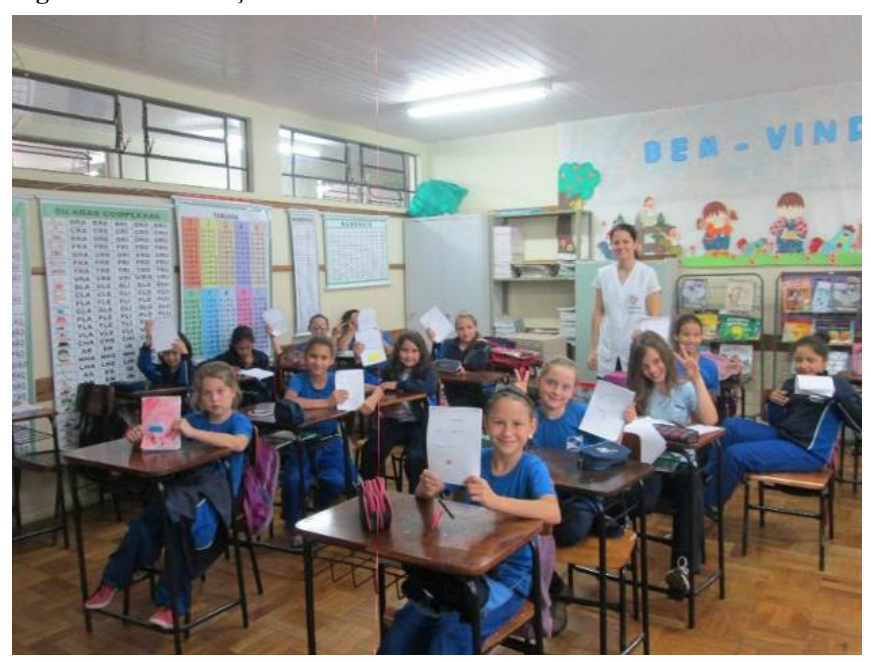

Fonte: Acervo das autoras.

A partir das observações, da socialização de experiências e saberes com o professor regente da turma, cada acadêmico, amparado e orientado por uma das professoras da UEPG, escolhe uma temática para desenvolver com os alunos da turma que acompanha, oportunizando, assim, a construção do conhecimento de forma coletiva e sistematizada, planejando os diferentes momentos de uma aula.
Deve-se ressaltar a riqueza desse processo, no sentido de que os licenciandos têm a oportunidade de vivenciar a docência de modo mais seguro, pois conhecem as características, expectativas e necessidades dos estudantes e professor da turma com a qual trabalharão, assim como seus ritmos de aprendizagem, fragilidades e preferências. Assim, os acadêmicos têm a possibilidade de personalizar o planejamento, "de modo a atender à grande parte das necessidades pedagógicas que se apresentam", pois tiveram tempo e oportunidades para refletir sobre o processo ensino-aprendizagem da turma que acompanharam durante as atividades do projeto (FARIAS, 2009, p. 111).

Em Garcia (2012, p. 39-40), localizam-se argumentos coerentes no que respeita às mudanças que podem se concretizar por meio de ações extensionistas:

\begin{abstract}
As mudanças são possíveis a partir do momento em que nos preparamos para elas. Quando oportunizamos o contato com a realidade, abrimos espaço à reflexão para além dos saberes e fazeres profissionais que se embasam, muitas vezes, somente em estudos teóricos e em resultados de pesquisas sobre determinado objeto. Precisa-se oferecer tempo para que os futuros profissionais contatem a realidade para além do universo teórico e percebam que há urgência em um repensar sobre as práticas para que passemos a ter uma relação de afeto com o mundo em que vivemos.
\end{abstract}

No caso do projeto de extensão, as mudanças, as compreensões sobre a docência, o ensino, podem ser percebidas aqui, nesse caso específico, a partir da leitura de uma das narrativas elaborada por uma acadêmica do curso de licenciatura em Pedagogia da UEPG, participante do projeto de extensão aqui relatado, a qual acompanhou uma turma do $4^{\circ}$ ano do Ensino Fundamental em uma escola municipal da cidade de Ponta Grossa - PR.

Em suas palavras, a referida licencianda, denominada como L1, relatou os pontos positivos sobre a postura da professora que ela acompanhava, durante uma aula de Língua Portuguesa em que as crianças deveriam ler $\mathrm{e}$ analisar um poema. A acadêmica assim escreveu sobre suas observações:

[...] Percebi que a professora sempre incentiva os
alunos a raciocinarem sobre as questões que surtem
dúvidas e nunca oferece respostas prontas. Além disso,
ela sempre questiona as crianças, relacionando o que
está sendo trabalhado no momento com conteúdos do
dia a dia dos alunos. Achei fantástica essa postura da
professora, pois esse comportamento normalmente não
é observado na maioria dos docentes.
A professora promoveu a reflexão sobre o sentido do
poema, proporcionando espaço para as crianças
relatarem suas impressões. Elas contribuíram com a
discussão e corrigiram os exercícios propostos
anteriormente de forma coletiva.

Deve-se ressaltar que essa proposta oportuniza aos acadêmicos espaço para vivenciar as práticas pedagógicas das instituições escolares, constituindo-se, assim, o referido projeto em uma excelente oportunidade para desenvolver a docência de modo pleno, consciente e significativo. Sobre isso, Garcia (2012, p. 20) enfatiza que:

Considerando as possíveis contribuições da extensão para a formação de docentes, compreende-se que "os conhecimentos de diferentes naturezas" podem ser potencializados pela participação dos acadêmicos das licenciaturas em atividades de extensão, proporcionando um contato prévio, antes mesmo do estágio curricular obrigatório, podendo auxiliar, principalmente, nas 
habilidades do ensinar e de se relacionar com os futuros espaços de atuação profissional.

Corroborando com o exposto no excerto acima, a acadêmica do curso de licenciatura em Pedagogia novamente explicita a relevância desse contato com a escola para o exercício da docência. Em outra narrativa sobre as observações realizadas no ambiente escolar, ela relata:

Após o intervalo, outra professora corregente assumiu as turmas unidas e trabalhou o conteúdo de saúde e corpo humano com as crianças. Notei que a forma totalmente diferente de prática pedagógica transformou o semblante da turma, pois essa professora interage com os alunos, pergunta coisas pra eles o tempo todo, usa bom humor para explicar conceitos simples e eles adoram.

Constatei que a diferença de conduta da aula de uma professora para a outra faz toda a diferença. As crianças se divertem e aparentam entender os conteúdos. Muito bom!

Desse modo, fui embora da escola hoje pensando em como motivar os alunos, como tornar as aulas atrativas e menos cansativas e descobri que tudo isso depende muito de nossa postura e de nosso desprendimento em valorizar o que as crianças trazem de informações.

Muitos professores ignoram as falas das crianças, no entanto, essas falas, muitas vezes, são ricas e cabe a nós, professores, mediadores do conhecimento, ter a "esperteza", a sensibilidade de aproveitar esses "ganchos" e tornar a aula significativa para nossos alunos.

Também fazem parte das atividades dessa proposta os encontros mensais entre os membros do grupo, compostos pelos atores citados anteriormente. Essas reuniões ocorrem nas dependências da UEPG bloco Central. Nesses encontros, previamente agendados, privilegia-se o processo de estudos e problematizações sobre as temáticas que emergem das narrativas produzidas pelos licenciandos. Sobre essa condução, André (2010, p. 177), ao discutir sobre a formação de professores, defende que:

Para tentar superar as limitações de tempo sem grande comprometimento da qualidade, seria interessante tornar mais efetivos os grupos de pesquisa, que possibilitam trabalhos conjuntos, com referenciais teóricos comuns e recortes específicos passíveis de aprofundamento. Para que se consiga bons resultados, entretanto, é crucial o papel dos orientadores, a quem caberia a coordenação dos grupos para fazê-los cumprir as metas desejadas.

Nos estudos e debates, sob a coordenação dos professores formadores, dentre aquelas que se constituíram objeto de discussão, destacamos as seguintes temáticas e referenciais:

Quadro 1 - Temáticas e referenciais.

\begin{tabular}{|l|l|}
\hline \multicolumn{1}{|c|}{ Temáticas } & \multicolumn{1}{c|}{ Referenciais } \\
\hline Narrativas na formação de professores & $\begin{array}{l}\text { Alves (2007); Welfort (1996); Weffort (1996); Reis (2008); } \\
\text { Oliveira (2011). }\end{array}$ \\
\hline Ensino e formação de professores & $\begin{array}{l}\text { Mizukami (1986); Pimenta (2005); } \\
\text { Freire (2013, 2014, 2015). }\end{array}$ \\
\hline Processo didático & Veiga (2006); Libâneo (2013); Farias (2009). \\
\hline A Pedagogia diferenciada no processo ensino-aprendizagem & Mainardes (1999; 2007). \\
\hline Planejamento didático & Masetto (1999); Inforsato; Robson (2011); Farias (2009). \\
\hline
\end{tabular}

Fonte: As autoras (2018)

No momento dos encontros, articulam-se os referenciais teóricos com as experiências vivenciadas pelos acadêmicos no acompanhamento das atividades nas salas de aulas das escolas parceiras em que esse projeto se concretiza. Evidencia-se a mediação de docentes da UEPG e também a colaboração dos professores da Educação Básica, os quais são convidados para participarem dessas reuniões. Sobre essa troca de olhares, a aproximação entre Educação Básica e Ensino Superior, Garcia (2012, p. 36) analisa que:

A universidade é mesmo esse lugar propício para socializar, descobrir, construir conhecimento, mas, sobretudo, é espaço para dialogar sobre o conhecimento, para questioná-lo, para descobrir que ele pode não ser gerado somente pela universidade, mas também pelos atores que fazem parte do cotidiano desse espaço "privilegiado" para o desenvolvimento de saberes.

Após o encontro mensal, os acadêmicos elaboram uma síntese sobre os aprendizados em cada reunião, refletindo sobre os pontos/aspectos fortes, significativos, que merecem maior atenção no decorrer da formação acadêmica, além de enfatizar os pontos frágeis/desafios presentes na profissão docente, com o objetivo de investigar, ampliar os conhecimentos, com vistas a sanar essas lacunas.

Nessa produção, os acadêmicos podem expressar suas inquietações, mesclando suas impressões a partir do referencial teórico discutido, relacionando esse processo de escrita com o diálogo e o relato de experiências de profissionais experientes na atividade docente. Os registros dos acadêmicos são compartilhados em uma página em rede social, da qual participam professores e licenciandos. Sendo assim, a partir destas produções são definidos os encaminhamentos e a seleção de temas de estudo, bem como seu conteúdo pode vir a constituir fonte de análise nas produções de artigos entre os partícipes do projeto. Vale salientar que os docentes da Educação Básica também são convidados a elaborarem suas sínteses e compartilhar com o grupo.

Evidencia-se também o incentivo do projeto à participação em eventos científicos, uma vez que as discussões do grupo incitam a pesquisa, favorecendo a análise crítica e o desenvolvimento da postura investigativa, colaborando, também, com o desenvolvimento da atitude de professor pesquisador de sua própria prática, conforme as indicações de Diniz-Pereira (2016, p. 148-149):

\begin{abstract}
A formação do "professor investigador" deveria resultar da vivência do licenciando, durante a sua trajetória na universidade, da pesquisa como processo, o que faz com que o futuro professor não só aprendesse o produto mas também apreendesse o processo de investigacão e, o mais importante, incorporasse a postura de investigador no seu trabalho cotidiano na escola e na sala de aula.
\end{abstract}

Além disso, na perspectiva do autor, a formação de professores constitui-se em um processo de investigação tão relevante que deveria ser compreendido como objeto de pesquisa, possibilitando reflexão constante sobre a formação docente, permitindo, assim, traçar novos percursos e estratégias sempre que necessário. Seguindo essa ótica, a avaliação seria elemento imprescindível nessa empreitada, pois:

[...] todo programa de formação de educadores deveria constituir-se em objeto de pesquisa na instituição formadora. Projetos de investigação sobre a formação docente permitiriam não só refletir sobre a preparação que está sendo realizada nessas instituiç̃es, mas, fundamentalmente, reconstruir a proposta de formação delas. A avaliação assumiria um papel essencial nesse tipo de pesquisa e constituiria um componente importante na reconstrução do próprio processo de formação de professores. (DINIZ-PEREIRA, 2016, p. 149). 
Figura 5 - Participação em eventos científicos.

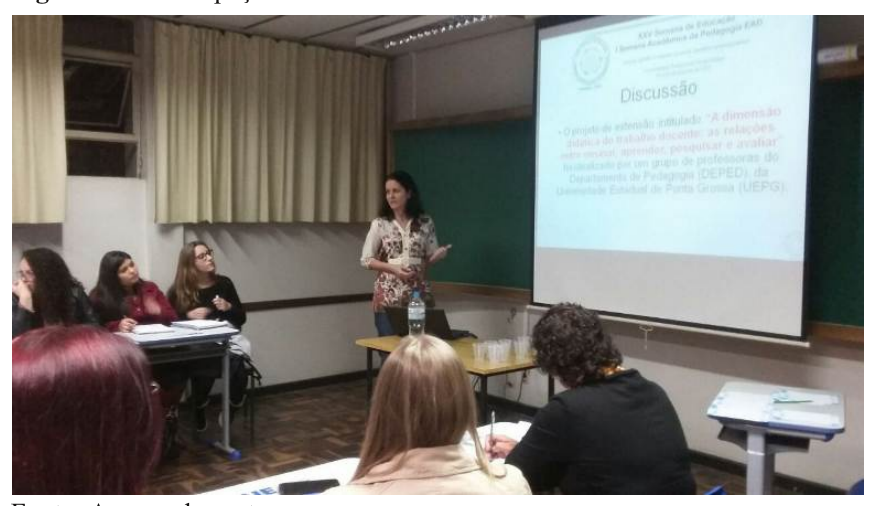

Fonte: Acervo das autoras.

Dessa forma, percebe-se que o referido projeto de extensão adota referenciais que expressam as compreensões sobre desenvolvimento profissional e formação de professores, estimulando, por meio das ações propostas, a troca de experiências, a socialização de saberes e o debate entre os acadêmicos e os professores da Educação Básica, por meio da aproximação com a realidade docente, vivenciando o dia a dia da sala de aula e das escolas.

Além disso, o grupo de estudos constituído como parte das atividades aqui descritas fomenta a pesquisa sobre as práticas pedagógicas, ao mesmo tempo que oportuniza espaço para a reflexão, articulando saberes teóricos e práticos.

\section{Considerações Finais}

Com vistas a finalizar esta produção, tecem-se algumas considerações, iniciando-se pela compreensão sobre extensão. A partir das contribuições de diferentes autores já nomeados no texto, reconhece-se que "extensão" não é sinônimo de mera divulgação de conhecimentos produzidos na academia junto à comunidade, mas em oposição a esta ideia, é imprescindível que as ações dessa natureza sejam concebidas como ações que privilegiem a escuta, a relação dialógica e a necessária indissociabilidade com o ensino e a pesquisa.

Dessa forma, pretende-se promover a aproximação entre instituição de Ensino Superior e Educação Básica, com vistas à construção, ressignificação e consolidação de saberes necessários ao exercício da docência, favorecendo a formação inicial e continuada, reconhecendo que todos os partícipes do projeto estão em processo formativo (GATTI, 2013-2014; DINIZ-PEREIRA, 2016; FREIRE, 1983; GARCIA, 2012).

Retomando o objetivo deste artigo, qual seja: apresentar aspectos relativos à extensão universitária e formação de professores acerca dos possíveis benefícios propiciados por projeto extensionista, especialmente junto aos licenciandos do Curso de Pedagogia da Universidade Estadual de Ponta Grossa (UEPG), destaca-se que são considerados pertinentes e significativos os encontros para estudos, os quais salientam temáticas afetas à área de Didática e Prática Pedagógica. Esses encontros favorecem a discussão e reflexão entre acadêmicos, professores da escola e professores da UEPG, potencializando espaços formativos que permitem a socialização de saberes e experiências na docência, bem como os desafios e dificuldades presentes no exercício da profissão.

Nesse sentido, o registro acima evidencia a dimensão dialógica que precisa ser considerada no desenvolvimento de projetos de extensão, reafirmando, portanto, a compreensão de Freire (1983) sobre dialogar, pois, segundo o autor, ser dialógico é estar permanentemente em busca da transformação da realidade, e não somente com o objetivo de determinar, impor, pois ser dialógico envolve a escuta, com a percepção consciente da realidade.

Também cabe ressaltar que as observações participativas junto aos professores da Educação Básica permitem ao licenciando uma reflexão sobre os conhecimentos apreendidos no decorrer de sua formação, o estabelecimento de relações entre os saberes requeridos pela docência e a prática pedagógica, contribuindo para que o ato de planejar o ensino tenha novos contornos e significados, reconhecendo que este é inerente ao trabalho docente.

Já no que respeita à pesquisa, a licencianda em questão registra que as ações extensionistas - as observações participativas, os encontros mensais de estudos, a produção das narrativas, o processo de planejamento das intervenções junto aos estudantes da Educação Básica - propiciam momentos de análise e ponderação, que desencadeiam, dentre outros aspectos, a elaboração de questionamentos e problematizações que geram produções sobre a docência e sobre a formação profissional (DINIZ-PEREIRA, 2016).

Mediante as discussões elencadas nesta produção, a partir das compreensões sobre extensão universitária e formação de professores, evidencia-se o necessário desenvolvimento de ações extensionistas, no sentido de contribuir com a formação dos licenciandos, estreitando as relações entre instituição de Ensino Superior e as escolas de Educação Básica, articulando-se ao ensino à pesquisa.

Finalizando, pode-se inferir que os caminhos a serem descortinados pela extensão universitária, no que respeita às contribuições para a formação de professores, ainda se revestem de complexidade e requerem a continuidade de estudos e pesquisas, para que a extensão se consolide amplamente no contexto universitário, a partir do desenvolvimento de um olhar criterioso e cuidadoso para com o disposto na meta 12.7 do Plano Nacional de Educação:

\section{[...] assegurar, no mínimo, dez por cento do total de créditos curriculares exigidos para a graduação em programas e projetos de extensão universitária, orientando sua ação, prioritariamente, para áreas de grande pertinência social. (BRASIL, 2014, p. 74).}

Trata-se de uma conquista significativa no âmbito da extensão, que pode adquirir sentido na formação de bacharéis e licenciandos se, de fato, sua inserção na carga horária dos cursos consiga promover a tão desejada aproximação da academia com a comunidade e que estas possam desenvolver ações colaborativas e conjuntas, articuladas ao ensino e à pesquisa, requerendo reflexão e ampla discussão, envolvendo diferentes segmentos da comunidade. 


\section{Referências}

ALVES, N. Nós somos o que contamos: a narrativa de si como prática de formação. In: BRASIL. Ministério da Educação. Salto para o futuro: histórias de vida e formação de professores, 2007, p. 69-78.

ANDRÉ, M. Formação de professores: a constituição de um campo de estudos. Revista Educação, Porto Alegre, v.33, n.3, p. 174-181, set./dez. 2010.

BRASIL. Lei 13.005, de 25 de junho de 2014. Aprova o Plano Nacional de Educação e dá outras providências. Disponível em: $<$ http://www.planalto.gov.br/CCIVIL 03/ Ato20112014/2014/Lei/L13005.htm>. Acesso em: $\overline{3} 0 / 05 / 2018$.

DINIZ-PEREIRA, J. E. Formação de professores da Educação Básica no Brasil no limiar dos 20 anos da LDBEN. Notandum 42. CEMOrOC, FEUSP - IJI Universidade do Porto, p. 139-160, set./dez. 2016.

FARIAS, I. M. S et al. Didática e docência: aprendendo a profissão. Brasília: Liber Livro, 2009.

\section{FÓRUM DE PRÓ-REITORES DE EXTENSÃO DAS} INSTITUIÇÕES DE EDUCAÇÃO SUPERIOR PÚBLICA BRASILEIRAS. Manaus, maio 2012. Disponível em: < http://www.utfpr.edu.br/estrutura-universitaria/proreitorias/prorec/diretoria-de-extensao/documentos-daextensao-de-ambito-nacional/politica-nacional-de-extensaouniversitaria-forproex-2012/view>. Acesso em: 30/05/2018.

GARCIA, B. R. Z. A contribuição da extensão universitária para a formação docente. 2012. $115 \mathrm{f}$. Tese (Doutorado em Educação) - Psicologia da Educação, Pontifícia Universidade Católica de São Paulo, São Paulo, 2012.

GATTI, B. A. A formação inicial de professores para a educação básica: as licenciaturas. Revista USP, São Paulo, n. 100, p.33-46, dez./jan./fev. 2013-2014.

FREIRE, P. Pedagogia do oprimido. 58. ed. Rio de Janeiro: Paz e Terra, 2014.

FREIRE, P. Pedagogia da autonomia: saberes necessários à prática educativa. 50 ed. Rio de Janeiro: Paz e Terra, 2015.

FREIRE, P. Educação e mudança. Rio de Janeiro: Paz e Terra, 2011.

FREIRE, P. Pedagogia da esperança: um reencontro com a pedagogia do oprimido. 13. ed. Rio de Janeiro: Paz e Terra, 2006.

FREIRE, P. Extensão ou comunicação? 7.ed. Rio de Janeiro: Paz e Terra. 1983.

FUJITA, M. S. L.; BARRAVIERA, B. Revista Ciência Em Extensão: 10 anos disseminando conhecimento e transformando a relação entre a Universidade e a Sociedade. Editorial. Revista Ciência em Extensão, v.10, n.3, p.2-4, 2014.

INFORSATO, E. C.; ROBSON, A. S. A preparação das aulas. In: UNIVERSIDADE ESTADUAL PAULISTA. Prograd. Caderno de Formação: formação de professores didática geral. São Paulo: Cultura Acadêmica, 2011, p. 86-99, v. 9.
LIBÂNEO, J.C. Didática. São Paulo: Cortez, 2013. p. 77-95.

MAINARDES, J. Projeto DiferenciAção: criando classes mais igualitárias por meio do trabalho diversificado. Ponta Grossa: UEPG, 2007. Disponível em: http://www.uepg.br/gppepe. Acesso em: 15/01/2018.

MAINARDES, J. Cenários de aprendizagem: instâncias interativas na sala de aula. In: MARTINS, J. B. (Org.). Na perspectiva de Vygotsky. São Paulo: Quebra Nozes, Londrina: Edições Cefil, 1999. p. 27-49.

MARCELO GARCÍA, C. Estudio sobre estratégia de inserción profesional em Europa. Revista Iberoamericana de Educación, Formación Docente, n.19, enero-abril, 1999, p. 1-34.

MASETTO, M. Didática: a aula como centro. São Paulo: FTD, 1997.

MIZUKAMI, M. G. N. Ensino: as abordagens do processo. São Paulo: E. P. U., 1986.

OLIVEIRA, R. M. M. A. Narrativas: contribuições para a formação de professores, para as práticas pedagógicas e para a pesquisa em educação. Revista de Educação Pública, v.20, n.43, Cuiabá, p.289-305, maio/ago. 2011.

PIMENTA, S. G. Epistemologia da prática ressignificando a didática. In: EGGERT, E. (Org.). Trajetórias e processos de ensinar e aprender: didática e formação de professores: livro 1. Porto Alegre: EDIPUCRS, 2008. p. 602-625.

REIS, P. R. As narrativas na formação de professores e na Investigação em educação. Nuances: Estudos sobre Educação. Presidente Prudente, ano XIV, v. 15, n. 16, p. $17-$ 34, jan./dez. 2008.

ROCHA, R. M. G. A construção do conceito de extensão universitária na América Latina. In: FARIAS, D. S. (Org.). Construção conceitual da extensão universitária na América Latina. Brasília: Universidade de Brasília, 2001, p. $13-29$.

RODRIGUES, A. L. L. et al. Contribuições da extensão universitária na sociedade. Cadernos de Graduação. Ciências Humanas e Sociais, Aracaju, v.1, n.16, p. 141-148, mar. 2013.

SANTOS, M. P. Contributos da extensão universitária brasileira à formação acadêmica docente e discente no século XXI: um debate necessário. Revista Conexão, UEPG, v.6, n.1, p.10-15, 2010.

VEIGA, I. P. A. Ensinar: uma atividade complexa e laboriosa. In: VEIGA, I. P. A. (Org.). Lições de didática. Campinas: Papirus, 2006. p.13-33.

WEFFORT, M. F. Observação, registro e reflexão Instrumentos Metodológicos I. São Paulo: Espaço Pedagógico, 1996. 